\title{
A INCONSTITUCIONALIDADE DE LEI ESTADUAL QUE CONCEDE GRATUIDADE NO TRANSPORTE COLETIVO INTERMUNICIPAL
}

\author{
ANDRÉ L. BORGES NETTO*
}

1. - Introdução - 2. - A desvalia jurídica da lei estadual $n^{\circ} 1.355 / 93$

- 3. - Conclusão

\section{Introdução}

Tradicional empresa de setor de transporte coletivo intermunicipal de passageiros, por força de contrato de concessão, solicitou a elaboração de estudo relativo a interessante questão de direito constitucional.

De uns anos para cá, além de se submeter aos encargos normais de um empreendimento comercial, a empresa está sendo obrigada a cumprir os termos da Lei Estadual $\mathrm{n}^{\circ} 1.355$, de 04 de janeiro de 1993, que concede gratuidade no transporte coletivo intermunicipal aos servidores públicos militares e aos servidores públicos da polícia civil.

Resolveu a empresa discutir a validade jurídica desta lei perante o Judiciário, especialmente porque veio a verificar (em tempos de economia estável, de baixa liquidez dos ativos financeiros, de redução do lucro das atividades comerciais e de aumento dos encargos) que o cumprimento da regra da gratuidade do transporte coletivo a policiais militares e civis tem levado a uma significativa redução do seu faturamento, comprometendo seriamente sua solidez financeira.

Não se pretende criticar ou discutir o objetivo visado pelo legislador ao conceder a gratuidade no transporte coletivo aos policiais militares e civis. Critica-se, isto sim, a validade juridica de ato normativo que transfere a empresa privada o ônus ou o encargo que deve ser assumido diretamente pelo Estado, pois a este incumbe a obrigação de prestar serviços de SEGURANÇA PÚBLICA e, em conseqüência, de transportar ou de pagar o transporte dos servidores vinculados a este setor.

* Advogado constitucionalista (Campo Grande/MS).

R. Dir. Adm.,

Rio de Janeiro, 221: 133-140,

jul./set. 2000 
Eis aí. pois, a questão que irá merecer nossa atenção: Lei Estadual transferiu à empresa privada o ônus de transportar policiais militares e civis por todo o Estado, sem repassar ou sem permitir qualquer tipo de contraprestação pelo serviço prestado. Situação como esta parece ser absolutamente irregular, sob o ponto de vista constitucional, pois não se permite, antes se veda, que o legislador (seja ele estadual ou federal) imponha a empresa privada ônus desta natureza sem a correspondente contraprestação.

Pretende-se, pois, afastar a incidência (via medida judicial) da Lei Estadual em relação à atividade comercial desenvolvida pela empresa (desobrigando-a de se submeter à concessão de passagens gratuitas aos policias militares e civis), em razão da flagrante inconstitucionalidade daquele ato normativo, conforme restará sustentado na seqüência.

Inexistem impedimentos à concessão daquilo que iremos sugerir (a título de ajuizamento de demanda), haja vista que se pretende questionar a validade constitucional de lei estadual na via do controle difuso, concreto ou incidental de constitucionalidade das leis, reconhecido pela doutrina como modalidade de fiscalização da validade de atos normativos exercido por qualquer órgão judicial, no curso de processo de sua competência e cuja decisão tem o condão, apenas, de afastar a incidência da norma viciada (cf. GILMAR FERREIRA MENDES, "Controle de Constitucionalidade", Ed. Saraiva, 1990, p. 202).

\section{A desvalia jurídica da lei estadual $n^{\circ} 1.355 / 93$}

A empresa vem sendo obrigada a conceder passagens gratuitas aos policiais militares e civis por força de normas contidas na Lei Estadual $n^{\circ} 1.355 / 93$. Tal obrigação, no entanto, é inválida, diante da inconstitucionalidade de referido ato normativo.

Norma jurídica inválida, como se sabe, não pode impor nada a ninguém, pois o que é nulo não pode produzir efeitos jurídicos. Como já teve oportunidade de decidir o STF, "a superioridade normativa da Constituição traz, ínsita, em sua noção conceitual, a idéia de um estatuto fundamental, de uma 'fundamental law', cujo incontrastável valor jurídico atua como pressuposto de validade de toda a ordem positiva instituida pelo Estado" (RTJ 140/954).

Pois bem, a desvalia jurídica da Lei Estadual $n^{\circ} 1.355 / 93$, que está a impor obrigação indevida à empresa, decorre, de início, da desatenção dos princípios fundamentais da LIVRE INICIATIVA e da PROPRIEDADE (art. $1^{\circ}, \mathrm{IV}$, da CF/88), que vêm repetidos e enfatizados em outras oportunidades ("caput" do art. $5^{\circ} \mathrm{e}$ "caput", parágrafo único e inciso II do art. 170 da CF/88). Daí decorre a conclusão de que "não só aqui, como no mundo ocidental em geral, a ordem econômica consubstanciada na Constituição, não é senão uma forma econômica capitalista, porque ela se apóia inteiramente na apropriação privada dos meios de produção e na iniciativa privada" (JOSÉ AFONSO DA SILVA, "Curso de Direito Constitucional Positivo", Ed. Saraiva, $9^{a}$ ed., p. 666). 
Ora, não pode deixar de ser considerado que a intervenção do Estado na atuação mercantil da empresa (impondo-lhe, sem contraprestação, ônus relativo à concessão de passagens gratuitas de transporte coletivo) está a ferir de morte os princípios da livre iniciativa e da propriedade, pois restou criada OBRIGAÇÃO NOVA que está a reduzir drasticamente o faturamento da empresa e em consequência o seu lucro, características de sua atuação mercantil que estão em sintonia com a ordem constitucional em vigor.

Ao Estado incumbe a prestação do serviço de SEGURANÇA PÚBLICA, cabendo-lhe, ainda, como decorrência lógica, suportar o ônus relativo ao transporte de seus servidores. Como, pois, entender pela não violação dos princípios destacados acima quando se verifica que não existe na Lei $1.355 / 93$ absolutamente nenhuma previsão quanto à remuneração da concessionária do serviço público pelo fato de ter sido criada obrigação nova e que não existia à época da assinatura do contrato?

Obrigação como a que se pretende combater sequer possui caráter tributário, pois não se amolda a nenhuma das modalidades previstas no art. 145 da Constituição Federal (especialmente porque a Lei $1.355 / 93$ não possui todos os requisitos necessários para que se considere existente um tributo - tal como base de cálculo, sujeito ativo e passivo, alíquota, hipótese de incidência etc, não se tratando, inclusive, de prestação pecuniária, tal como exige $o$ art. $3^{\circ}$ do CTN). Em verdade, o ônus repassado à empresa mais se assemelha a uma espécie de CONFISCO ou de DESAPROPRIAÇÃO INDIRETA, sem pagamento de qualquer espécie de indenização, algo que é sabidamente inválido.

Observe-se que não se desconhece a autorização constitucional para intervenção do Estado no domínio econômico. Ocorre que isto somente se dá, validamente, quando o Poder Público exerce as funções de fiscalização, incentivo e planejamento ("caput" do art. 174 da CF/88), sendo-lhe lícito, também, via Poder Legislativo, "reprimir o abuso do poder econômico" ( $\$ 4^{\circ}$ do art. $174 \mathrm{da} C F / 88$ ), algo que, à toda evidência, está fora de cogitação, porquanto se está a tratar não de correção de conduta comercial irregular mas sim de atuação imprópria do Estado-legislador, que impôs ônus pesadíssimo a empresa regida pelas leis de mercado sem a necessária contraprestação.

JOSÉ AFONSO DA SILVA, notável constitucionalista pátrio, bem abordou a questão da limitação da intervenção estatal no domínio econômico, "in verbis":

"Se a constituição econômica, traduzida no direito constitucional positivo, é essencialmente capitalista, fundada na livre iniciativa e na livre concorrência, a faculdade de intervenção e participação estatal no domínio econômico constitui apenas um modo de temperamento do sistema" ("Curso de Direito Constitucional Positivo", Ed. RT, $2^{2}$ ed., p. 506).

Não se quer dizer que ao Estado é vedada a concessão do privilégio estabelecido pela Lei $1.355 / 93$. Isto até que seria válido, desde que se tivesse indicado a fonte estatal necessária para o custeio da gratuidade de passagens de transporte coletivo, TUDO PORQUE A REGRA DA ATUAÇÃO DAS EMPRESAS MERCANTIS, pelo que se vê dos dispositivos constitucionais retrocitados, É A LIBERDADE 
(decorrente da livre iniciativa) e em razão disso elas estão sempre autorizadas a cobrar pelos serviços que desenvolvem. QUALQUER RESTRIÇÃO A ESTA REGRA HÁ DE DECORRER DA PRÓPRIA CONSTITUIÇÃO OU DE LEIS EDITADAS COM FUNDAMENTO NELA (cf. CELSO RIBEIRO BASTOS, “Comentários à Constituição do Brasil", $7^{\circ}$ vol., Ed. Saraiva, p. 17).

Exemplo da correta aplicação dos princípios jurídicos destacados acima pode ser extraído da LIMINAR concedida pelo dedicado Magistrado da $2^{*}$ Vara de Fazenda Pública de Campo Grande, que, recentemente, analisando medida cautelar incidental proposta por empresa de promoções artísticas - que combate a validade jurídica de Lei Estadual que concedeu aos estudantes o benefício da meia entrada em cinemas e em outros eventos culturais --, veio a considerar que "os argumentos expostos na inicial são consistentes, uma vez que o art. 170 da Constituição Federal, ao elencar os principios que norteiam a ordem econômica, determina, dentre outros, que sejam respeitados a propriedade privada, a livre concorrência e a defesa do consumidor. (...) Ninguém é contrário que se proporcione incentivo à cultura $e$, tampouco, se desconhece as dificuldades financeiras pelas quais todos atravessam nesses momentos dificeis da economia. CONTUDO, O ESTADO, A QUEM INCUMBE APOIAR E INCENTIVAR A VALORIZAÇÃO E A DIFUSÃO DAS MANIFESTAÇÕES CULTURAIS (ART. 125, 'CAPUT', DA CF), NĀO PODE TRANSFERIR O ENCARGO À INICIATIVA PRIVADA SEM OFERECER QUALQUER CONTRAPRESTAÇÃO" .

Também sobre a questão da inconstitucionalidade das leis que estipularam cobrança de meia entrada dos estudantes nos cinemas existe LIMINAR que foi concedida no Mandado de Segurança $n^{\circ}$ 001756-8, proferida pelo Desembargador José Antônio Amorim (TJ/SP), do seguinte teor:

"Objetiva o impetrante do presente mandado de segurança, a exclusão do encargo que lhe foi imposto pela Lei Estadual n' 10.859/91, que criou a 'meia entrada' para estudantes, em eventos artísticos. Argüiu o impetrante que o Governo do Estado, ao instituir esse incentivo, o fez sem assimilar os altíssimos custos que estavam sendo imputados às empresas do setor. Não se tem notícia de que o Governo do Estado, por qualquer forma, tenha procurado aliviar a carga decorrente do incentivo, mediante a concessão de subsidio, ao menos parcial aos promotores de eventos. Nesse passo não parece correto carrear àqueles todo o ônus do financiamento da cortesia que o Estado cuida em patrocinar. Alega o impetrante a inconstitucionalidade da medida, posto que o Estado, assim procedendo, pratica intervenção no domínio econômico, o que é perfeitamente discutivel, até porque, no nosso ordenamento jurídico constitucional só se encontram regras de apoio e incentivo à livre iniciativa. Presentes os pressupostos, defiro a liminar, para excluir o impetrante da obrigatoriedade de praticar a 'meia entrada' nos eventos que promover até decisão do mérito do presente mandado de segurança."

Os argumentos elencados por aqueles ilustres Magistrados vêm de encontro com os que aqui estão sendo sustentados, a saber: lícito seria a instituição do benefício 
e a transferência do ônus ao particular, desde que prevista a necessária contraprestação.

Demonstração de clara observância da Constituição Federal foi dada pelo legislador do Estado de Goiás, que ao editar a Lei $n^{\circ} 12.313 / 93$, estabelecendo gratuidade de tarifas para os usuários do transporte coletivo urbano, veio a estabelecer a necessidade de o Poder Público assumir os encargos relativos ao benefício criado (cf. art. $2^{\circ}$ ). Como em nosso Estado o mesmo não veio a ocorrer, por absoluta desatenção àquilo que já se sustentou, tem-se como certa a desvalia constitucional do ato normativo ora impugnado.

Convém dizer, ainda a título de ilustração, que para fazer valer o benefício constitucional da gratuidade do transporte coletivo urbano para os idosos $\left(\S 2^{\circ}\right.$ do art. $230 \mathrm{da}$ CF/88), no Estado de Mato Grosso do Sul editou-se a Lei $\mathrm{n}^{\circ} 1.542 / 94 \mathrm{e}$ a Norma Complementar $n^{\circ} 01 / 96$ do DERSUL, que estipularam LIMITAÇÕES CLARAS ao exercício daquele privilégio, até como forma de vedar o ABUSO. Com efeito, referidos atos estabeleceram limitações quanto ao número de viagens (apenas 10 viagens anualmente, art. $4^{\circ}$ ) e quanto ao número de poltronas a serem reservadas em cada ônibus (poltronas de $\mathrm{n}^{\circ} 03$ e de $\mathrm{n}^{\circ} 04$ de cada veículo de transporte).

Mais se reforça a inconstitucionalidade da Lei Estadual $n^{\circ} 1.355 / 93$ quando, comparando suas prescriçöes normativas com as contidas nos atos indicados no item anterior, verifica-se que a mesma não estipulou absolutamente nenhuma limitação para o exercício do privilégio ali estatuído. Ou seja: nada restou previsto legislativamente quanto à necessidade de ser limitado o número de policiais militares e civis nos ônibus da empresa e também nada se estipulou quanto ao número de viagens anuais a serem permitidas com relação aos mesmos servidores. Tudo, pois, está a demonstrar ser realmente inválida a lei questionada, por desatenção clara e grave ao princípio constitucional da iniciativa privada e por ingerência indevida do Estado na ordem econômica.

Outro aspecto de natureza constitucional não pode ser deixado de lado (e que reforça a necessidade de ser reconhecida a inconstitucionalidade da Lei 1.355/93), a saber: com a criação de encargo novo, que não existia à época da assinatura dos contratos de concessões de linhas de transporte coletivo (cópias em anexo), HOUVE NÍTIDO DESEQUILÍBRIO ECONÔMICO-FINANCEIRO, pois não se indicou e não se autorizou nenhuma forma de a empresa repassar ao Estado o valor das passagens gratuitas que vêm sendo fornecidas diariamente.

Sabido é que " na concessão de serviço público é lícita a modificação pelo poder concedente do funcionamento do serviço desde que fique assegurado o equilibrio do contrato" (RTJ 46/144). Também não se desconhece a célebre lição doutrinária no sentido de que, perante o concedente, "os direitos do concessionário cifram-se ao respeito à parte contratual da concessão, isto é, à manutenção do equilíbrio econômico-financeiro e também a que não lhe seja exigido, sob cor de cumprimento de suas obrigações, o desempenho de atividade estranha ao objeto da concessão, pois é o objeto que identificará tal ou qual concessão" (CELSO ANTONIO BANDEIRA DE MELLO, "Prestação de Serviços Públicos e Administração Indireta", Ed. RT, $2^{2}$ ed., p. 42). 
Da leitura do ato normativo sob análise verifica-se o sentido desequilíbrio que ele provocou na relação contratual mantida entre empresa e Estado, com desatenção violenta à regra legal (art. $9^{\circ}$ da Lei Federal $\left.n^{\circ} 8.987 / 95\right)$ e constitucional (inciso XXI do art. $37 \mathrm{da} \mathrm{CF} / 88$ - “...mantidas as condiçōes efetivas da proposta") do equilíbrio econômico-financeiro. Fato é que houve alteração da relação encargo-remuneração, que deveria ser mantida durante toda a execução dos contratos firmados entre as partes. Como foi violado o direito da concessionária de ver mantida a equação financeira originariamente estabelecida, cabe ao Judiciário invalidar o ato ilicitamente produzido pelo Parlamento Estadual e que vem sendo cumprido pelo Estado.

Existe precedente do E. Tribunal de Justiça de São Paulo no mesmo sentido, quando se declarou inconstitucional lei municipal que dispensou as pessoas com mais de 60 anos de idade do pagamento da tarifa do transporte coletivo urbano, tendo sido firmado o entendimento de que “... a lei municipal guerreada não indica a fonte de recursos disponiveis para fazer frente à despesa criada com a dispensa de recolhimento das tarifas, ofendendo, nitidamente, o art. 25 da Carta Estadual".

Noção como a extraída deste acórdão bem demonstra que não seria difícil, repita-se, tornar a Lei Estadual no 1.355/93 compatível com a Constituição Federal. Bastaria que este ato normativo indicasse " a fonte de recursos disponiveis para fazer frente à despesa criada com a dispensa de recolhimento das tarifas". Como isto não ocorreu (e como não é dado ao Judiciário, infelizmente, atuar como legislador positivo), não há como deixar de reconhecer o vício da inconstitucionalidade em discussão, daí decorrendo a nulidade absoluta daquilo que foi produzido pelo legislador estadual.

Os exemplos de correta observância da Constituição Federal não acabam. Vejase a questão da propaganda eleitoral gratuita, que é transmitida OBRIGATORIAMENTE pelas empresas concessionárias de serviços públicos de telecomunicações. Seria o caso de perguntar se tais empresas, ao realizarem a divulgação, em horário nobre, da propaganda eleitoral (supostamente gratuita), estariam assumindo tal encargo em nome do Poder Público sem qualquer contraprestação. A resposta, pelo que se vê de leis que sempre são editadas por ocasião das Eleições (tal como a Lei Federal $n^{\circ} 8.173 / 93$, regulamentada pelo Decreto $n^{\circ} 1.976 / 96$ ), é no sentido de que as emissoras de rádio e televisão, obrigadas à divulgação "gratuita" de propaganda eleitoral, poderão excluir do lucro líquido, para efeito de determinação do lucro real, valor correspondente a oito décimos do resultado da multiplicação do preço do espaço comercializável pelo tempo que seria efetivamente utilizado pela emissora em programação destinada a publicidade comercial, no periodo de duração daquela propaganda $\left(\right.$ art. $1^{\circ}$ ).

Com mais este exemplo, que se aplica a concessionária de serviço público (tal como a consulente), parece ter ficado claro que o ato normativo estadual ora combatido não possui mesmo nenhuma validade jurídica. A Constituição Federal (especificamente quando este documento jurídico se refere ao princípio da livre iniciativa, ao direito de propriedade e ao equilíbrio economico-financeiro) foi amplamente desprezada pelo Parlamento Estadual, quando da inovação jurídica que se combate. 
Mas não é só. A doutrina de MARÇAL JUSTEN FILHO ("Concessões de Serviços Públicos", Ed. Dialética, 1997, p. 162) é bastante precisa ao abordar a questão da variação da tarifa em função da ausência de recursos do usuário ("tarifa social"), tal como se vê do parágrafo a que se pede atenção na leitura:

"A questão apresenta contornos distintos conforme se enfoque a prestação do serviço público efetivada diretamente pelo Estado ou por concessionário. É QUE O CONCESSIONÁRIO NÃO TEM O DEVER DE ARCAR, INDIVIDUALMENTE, COM CUSTOS REFERENTES À REDUÇÃO OU SUPRESSÃO DAS DESIGUALDADES ECONÔMICAS. Esses encargos devem ser repartidos entre todos os integrantes da comunidade, segundo o principio da isonomia. Pode-se supor que, desempenhado o serviço público diretamente pelo Estado, os efeitos econômicos das tarifas sociais acabam repassados à comunidade, segundo principios adequados. QUANDO SE PRETENDE, PORÉM, ESTABELECER TARIFA SOCIAL PARA SERVIÇOS PÚBLICOS CONCEDIDOS, NÃO SE PODE IMPOR AO CONCESSIONÁRIO QUE ARQUE, COM RECURSOS PESSOAS PRÓPRIOS, COM OS EFEITOS ECONÔMICOS CORRESPONDENTES. Deverá haver mecanismos, na concessão, de transferência dos custos da tarifa social para toda a comunidade. De regra, esse mecanismo não pode repassar o custo para a tarifa dos demais usuários. Se essa fosse a solução, os custos da tarifa social seriam partilhados entre os usuários do serviço. Ora, normalmente, nem todos os integrantes da comunidade são usuários. De todo modo, a transferência desses custos para a tarifa produziria outras distorçōes incompativeis com os princípios constitucionais, pois o consumo mais intenso de serviço público significaria assunção de encargos mais elevados. A SOLUÇÃO, PORTANTO, É O ESTADO CUSTEAR ESSAS TARIFAS SOCIAIS" (sem destaque no original).

O mesmo autor ainda cita o texto original do art. 12 da Lei das Concessões, QUE FOI VETADO PELO PRESIDENTE DA REPÚBLICA, que era bastante elucidativo e que estava em harmonia com o Texto Constitucional: “Art. $12-E$ vedado, ao poder concedente, estabelecer privilégios tarifários que beneficiem segmentos específicos de usuários do serviço concedido, exceto se no cumprimento de lei que especifique as fontes de recursos." O veto, certamente, só foi aposto em razão de já ser "tradição" no Brasil o Poder Público "dar esmola com o bolso alheio" ou a "fazer cortesia com o chapéu alheio".

Tem-se, ainda, que, descumprida a caraterística mais elementar do contrato de concessão (modalidade de contrato administrativo governado pelo princípio da remuneração e do equilíbrio da equação financeira), acabou sendo descumprida a garantia constitucional do ATO JURÍDICO PERFEITO (art. $5^{\circ}, \mathrm{XXXVI,} \mathrm{da} \mathrm{CF/88),}$ algo que certamente não será referendado pelo Judiciário Estadual, que tem sabido (como se vê da decisão noticiada acima) afastar a incidência de leis produzidas em descompasso com a Carta Magna. 


\section{Conclusão}

Pelo exposto, nossa conclusão é no sentido de que, para ser preservada a superioridade normativa da Constituição, necessária se faz a intervenção do Judiciário, que poderá (garantindo-se, evidentemente, a ampla defesa e o contraditório) declarar estar a empresa desobrigada a conceder gratuidade de transporte coletivo intermunicipal aos servidores públicos militares e aos servidores públicos da polícia civil, por força da inconstitucionalidade da Lei Estadual $n^{\circ} 1.355 / 93$, algo que deve ser perseguido via demanda judicial (em que se poderá postular, inclusive, a antecipação da tutela jurisdicional, diante da evidência do vício jurídico apontado).

Reconhecida a inconstitucionalidade, faculta-se à empresa o pedido de restituição de tudo que foi gasto indevidamente a título de cumprimento de lei inválida ${ }^{\text {. }}$

1 Nosso estudo foi transformado na inicial de uma ação de rito ordinário, que teve a tutela antecipada deferida (Juízo da $2^{2}$ Vara de Fazenda Pública de Campo Grande/MS, autos n ${ }^{\circ} 98.16009$ 4, Juiz Vladimir Abreu da Silva), acolhendo-se, ao final, via sentença, em outubro de 1999, tudo o que foi pedido, declarando-se, incidentalmente, a inconstitucionalidade da Lei Estadual $\mathbf{n}^{\circ}$ 1.355/93, desobrigando-se a empresa da concessão gratuita de passagens de transporte coletivo intermunicipal aos servidores públicos militares e aos servidores públicos da polícia civil. 